\title{
Penjadwalan Agenda Pelaksanaan Tridharma Perguruan Tinggi Secara Online Menggunakan Google Calendar
}

\author{
Untung Raharja ${ }^{1)}$, Ninda Lutfiani ${ }^{2)}$, Wahyu Setya Wardana ${ }^{3)}$ \\ 1,2,3) Sistem Informasi, STMIK Raharja \\ Jl. Jendral Sudirman No. 40 Modern Cikokol, Tangerang \\ Email : untung@raharja.inf ${ }^{1)}$,ninda@raharja.info ${ }^{2)}$ wahyu.setya@raharja.info ${ }^{3)}$
}

\begin{abstract}
Abstrak
Maju nya perkembangan teknologi yang berjalan saat ini berdampak cukup besar dengan kehidupan manusia sehari-hari. Tidak terkecuali pada bidang pendidikan. Saat ini banyak sekali perubahan perubahan yang ditunjang oleh berbagai teknologi baru. Banyak pula penunjang untuk mempermudah kegiatan pendidikan. Salah satunya yaitu kalender. Tidak hanya digunakan untuk melihat tanggal bulan dan tahun, kalender ternyata memiliki berbagai fungsi lainnya. Yaitu salah satunya berfungsi sebagai pengingat atau reminder. Selain itu bisa digunakan untuk membuat note atau catatan pada hari tersebut. Dari berbagai macam aktivitas atau kegiatan yang kita akan dan sedang dilakukan dapat di buat kan catatan dan pengingat dari setiap kegiatan tersebut. Setiap jadwal atau reminder yang sudah dibuat dapat juga menampilkan notifikasi pengingatnya. Penggunaan google calendar pun dapat digunakan oleh berbagai kalangan mulai dari murid Sekolah sampai Orang Tua sekali pun baik personal maupun kelompok atau organisasi. Penggunaanya juga terbilang mudah karena user interface nya yang userfriendly..
\end{abstract}

Kata kunci: Agenda Online Tridharma Google Calendar, Tridharma, Google Calendar.

\section{Pendahuluan}

Perkembangan teknologi yang bergerak cepat membuat kita perlu menyesuaikan dengan perubahan yang sudah ada. Kebutuhan akan hal hal yang berkaitan dengan kehidupan semakin banyak. Mulai dari kegiatan harian, mingguan sampai bulanan terkadang sampai kita kewalahan dengan agenda yang akan dan sedang kita jalani. Maka dari itu kita dituntut untuk mencari teknologi masa kini untuk membantu kita dalam menjalankan akitivitas kita sehari-hari. Perkembangan yang ada pun mendorong kita untuk terus belajar dan mencoba mengimbangi dengan perubahan-perubahan yang ada agar tidak tertinggal terlalu jauh. Hal ini dilakukan demi mempermudah kehidupan kita di masa mendatang.

Setiap orang memiliki aktivitas yang berbeda-beda setiap harinya. Pada umumnya semua aktivitas belum dapat di agenda kan dengan baik. Perlu adanya penjadwalan yang dapat mengorganisir semua kegiatan kita dengan baik.
Penjadwalan dapat diartikan pembuatan agenda kegiatan. Pada dasarnya penjadwalan mencakup pengurutan aktivitas, pengalokasian aktivitas pada fasilitas dan pemetaan aktivitas menurut urutan waktu. Tujuan penjadwalan adalah meningkatkan efektivitas dan efisiensi waktu, mengurangi terjadinya keterlambatan, dan dapat membantu pengambilan keputusan mengenai perencanaan kapasitas pabrik.

Dalam hal ini pada kegiatan Tridharma yang ada terdapat berbagai macam kegiatan yang diselenggarakan. Dari setiap kegiatan memiki rentang waktu dan jadwal yang berbeda. Hanya ada satu kali reminder pada saat awal kegiatan tersebut akan di laksanakan per satu periode. Selanjutnya tidak ada reminder atau pengingat kepada masing- mahasiswa saat menjalankan kegiatan Tridharma nya. Sehingga dalam menjalankan tridharma tersebut masih ada beberapa mahasiswa yang lupa.

Untuk menjawab masalah tersebut, maka dibuatlah agenda online yang memanfaatkan aplikasi besutan dari Google yaitu Google Calendar. Google Calendar adalah aplikasi web pengelolaan waktu dari Google. Aplikasi ini diluncurkan pada 13 April 2006 dan keluar dari fase beta pada Juli 2009. Pengguna perlu memiliki Google Account untuk menggunakan perangkat lunak ini. Masih terus mendapatkan pembaharuan dari segi dan tampilan pada platform ini. Aplikasi ini dapat membantu untuk membuat agenda online kegiatan Tridharma yang ada pada Perguruan Tinggi. Ada beberapa kegunaan lainnya selain untuk membuat agenda online. Tentunya cukup dengan menggunakan akun Google yang kita miliki.

Gmail(Google Mail) sebagai alat utama untuk membuat agenda online menggunakan google calendar tersebut. Yang mana penggunaan Gmail / Rinfo (raharja info) untuk saat ini sudah meluas hampir keseluruhan mahasiswa Perguruan Tinggi Raharja wajib memilikinya. Tentu saja ini akan memudahkan dalam hal komunikasi dengan seluruh pribadi raharja. ada beberapa langkah dalam pembuatan jadwal online pada Google Calendar ini. 


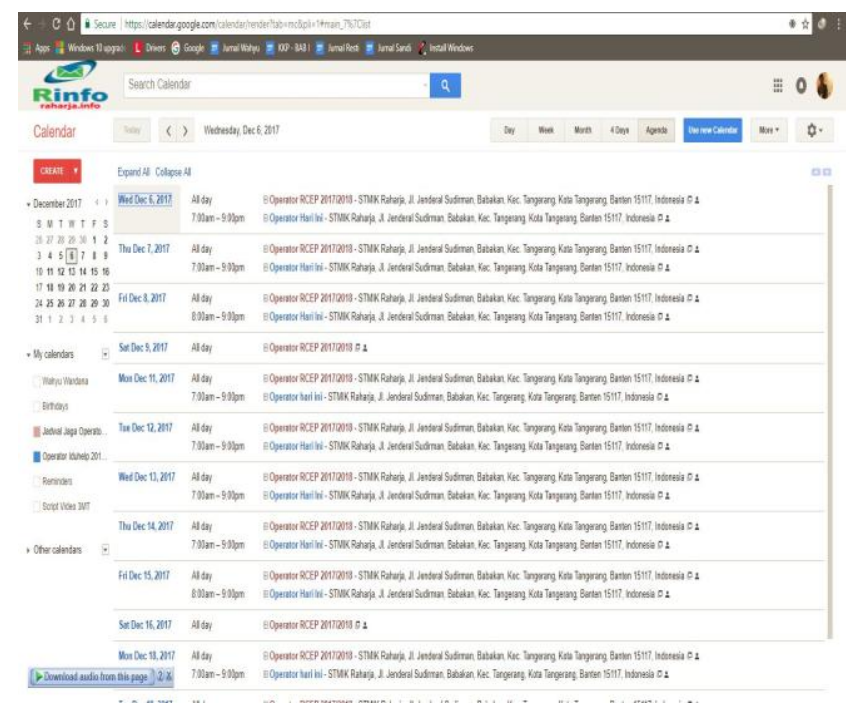

Gambar 1. Tampilan dari Google Calendar

Merupakan tampilan dari google calendar. Dimana pada beberapa tampilan berbeda. Dapat disesuaikan dengan kebutuhan. Mulai dari tampilan harian, mingguan, bulanan, tahunan dan sebagainya. Pada sebelah kiri merupakan Agenda agenda yang sudah ada atau sudah pernah di buat sebelumnya.

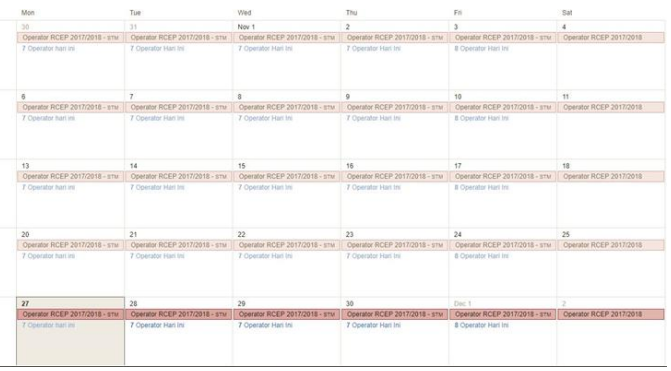

Gambar 2. Agenda yang sudah ada pada kalender

Agenda Online Tridharma yang sudah dibuat akan ditampilkan setiap harinya. Diatas merupakan halaman tampilan per satu bulannya.

\section{Metode Penelitian}

Teknik pengumpulan data yang dituangkan dalam pengumpulan data serta mengolah informasi yang diperlukan, menggunakan 2 (dua) metode yaitu:

1. Metode Observasi (Pengamatan Langsung), seperti halnya pengumpulan data dengan melakukan pengamatan pada suatu objek yang sedang diteliti dan diperlukan sebagai bahan untuk membuat laporan penelitian. Sehingga dapat terkumpulnya data informasi berupa berkas pendaftaran anggota dalam hal ini dianalisa untuk membangunan sistem pendaftaran.

2. Metode Studi Pustaka, yaitu metode yang digunakan untuk mendapatkan informasi dari beberapa sumbersumber literature seperti jurnal, makalah, internet, dan lain sebagainya yang berkaitan dengan penelitian sebagai bahan referensi, adapun referensi jurnal dalam pembuatan jurnal ini:
Penelitian yang telah dilakukan oleh Untung Rahardja, Khanna Tiara dan Ray Indra Taufik Wijaya (2014) berjudul "Penerapan Rinfo Sebagai Media Pendukung Untuk Proses Pembelajaran Pada Peguruan Tinggi Raharja". Rinfo calendar adalah sebuah online calendar juga salah satu tolls pengingat(reminder) dan juga dapat digunakan dan tidak perlu men-download perangkat lunak lainnya.

Penelitian yang telah dilakukan oleh Indri Handayani, Herrafika Kusumahati, Alpiah Nurul Badriah (2017) berjudul "Pemanfaatan Google Spreadsheet Sebagai Media Pembuatan Dashboard pada Official Site iFacility di Perguruan Tinggi“. iFacility merupakan tempat yang dapat memberikan informasiinformasi yang berguna dengan cepat dan tepat untuk mengambil sebuah tindakan atau keputusan dengan efektif dan efisien mengenai fasilitas yang dikelola secara online.

Penelitian yang dilakukan oleh M Mukhtar, I Wayan Mustika dan Noor Akhmad Setiawan (2017) berjudul "Perancangan Sistem Penjadwalan Untuk Manajemen Penggunaan Ruangan Berbaris Google Calendar" Sistem penjadwalan ini akan menggunakan google calendar sebagai acuan untuk jadwal aktivitas dalam ruangan san penggunakan zigbee sebagai jalur komunikasi antara aplikasi web dan perangkat yang akan dikontrol.

Penelitian yang dilakukan oleh Yody Ferdiansyah, Boko Susilo dan Desi Andreswari (2014) yang berjudul "Pemanfaatan Google Calendar Sebagai SMS Alert Dalam Sistem Monitoring Jaringan Komputer". Hasil akhir dari penelitian ini adalah sebuah sistem monitoring jaringan komputer yang mampu memberikan SMS alert sehingga administrator jaringan bisa mengetahui gangguan jaringan kapan saja dan dimana saja dan dapat menerima notifikasi jika terjadi gangguan jaringan.

Penelitian yang dilakukan oleh Taufik Ramadhan dan Victor G Utomo (2014) yang berjudul "Rancang Bangun Aplikasi Mobile untuk notifikasi Jadwal Kuliah Berbasis Android" Aplikasi seluler ini digunakan informasi jadwal di perangkat seluler mahasiswa, menghilangkan kebutuhan mahasiswa untuk datang ke kampus untuk mendapatkan informasi jadwal terbaru. Aplikasi ini juga memberi tahu siswa agar hadir.

Penelitian yang dilakukan oleh Guntoro Barovih (2016) berjudul "Desain Sistem Informasi Penjadwalan Laboratorium Terbuka". Metode perancangan yang digunakan dalam pengembangan sistem informasi penjadwalana laboratorium menggunakan waterfall model. Hasil dari penelitian ini adalah permodelan database sistem informasi pemakaian laboratorium yang digunakan sebagai acuan pengembangan sistem informasi.

Penelitian yang dilakukan oleh Indri Handayani, Herrafika Kusumahati, Alpiah Nurul Badriah (2017) berjudul "Pemanfaatan Google Spreadsheet Sebagai Media Pembuatan Dashboard pada Official Site iFacility di Perguruan Tinggi." iFacility merupakan tempat yang bisa memberikan informasi-informasi yang berguna dan 
mendapatkan informasi secara cepat dan tepat untuk mengambil tindakan atau keputusan secara efektif dan efisien tentang fasilitas yang dikelola secara online.

Penelitian yang dilakukan oleh Pulut Suryati dan Deborah Kurniawati (2016) berjudul "Aplikasi Penjadwalan Koas Dengan Metode Branch and Bound". Penjadwalan koas merupakan pengaturan dari beberapa koas yang dialokasikan pada beberapa unit dalam waktu atau periode tertentu. Yang mengusulkan rancang bangun aplikasi penjadwalan koas sebagai permasalahan integer programming yang diselesaikan dengan metode branch and bound. Tujuannya yaitu meminimalkan pelanggaran konstrain sebagai biaya pinalti dan fungsi kendala.

Penelitian yang dilakukan olehMara Destiningrum dan Qadhli Jafar Adrian berjudul "Sistem Informasi Penjadwalan Dokter Berbasis Web Dengan Menggunakan Framework CodeIgniter (Studi Kaus : Rumah Sakit Yukum Medical Center)". Hasil menunjukkan dapat disimpulkan bahwa dengan adanya sistem Informasi Penjadwalan Dokter Berbasis Web dengan menggunakan Framework Codeigniter dapat memberikan informasi jadwal praktik dokter dengan cepat dan akurat dan menjadikan proses penjadwalannya lebih efisien.

\section{Hasil dan Pembahasan}

Sudah bukan hal asing lagi bagi kita para pengabdi di dunia pendidikan khususnya para Pribadi Raharja/Mahasiswa Perguruan Tinggi Raharja menggunakan GoogleMail (Rinfo). Rinfo (Google Mail) merupakan portal utama dalam menjalankan kegiatan perkuliahan pada Perguruan Tinggi Raharja. Ada beberapa fungsi selain digunakan untuk mengirim dan menerima email.

Penggunaan nya yang sudah meluas yaitu ke seluruh civitas mahasiswa Perguruan Tinggi Raharja semakin mempermudah komunikasi antar penghuni kampus. Pada pembuatan agenda online ini pada dasarnya sangat mudah hanya membutuhkan akun gmail atau google mail sebagai alat utamanya. Setiap orang yang nantinya tergabung dapat berinteraksi dan saling berkomunikasi. Google Calendar telah digunakan oleh Perguruan Tinggi Raharja dalam berbagai kegiatan akademik, seperti dalam hal keuangan sebagai reminder pembayaran registrasi dan SKS, pengingat rapat kerja, digunakan juga sebagai pengingat bimbingan KKP maupun Skripsi.

Selain itu juga google calendar sudah digunakan untuk membuat reminder mengenai kegiatan tridharma yang ada pada Perguruan Tinggi. Yaitu pada kegiatan iDuhelp dan RCEP. Tampilan utama (interface) yang dapat digunakan adalah:

1. Memiliki Akun Gmail

Gmail merupakan alat utama yang digunakan untuk membuat agenda online pada kalender google. Halamannya bisa diakses disini http://mail.google.com/

2. Login gmail

Setelah berhasil login ke gmail, akan dihadapkan pada tampilan seperti ini

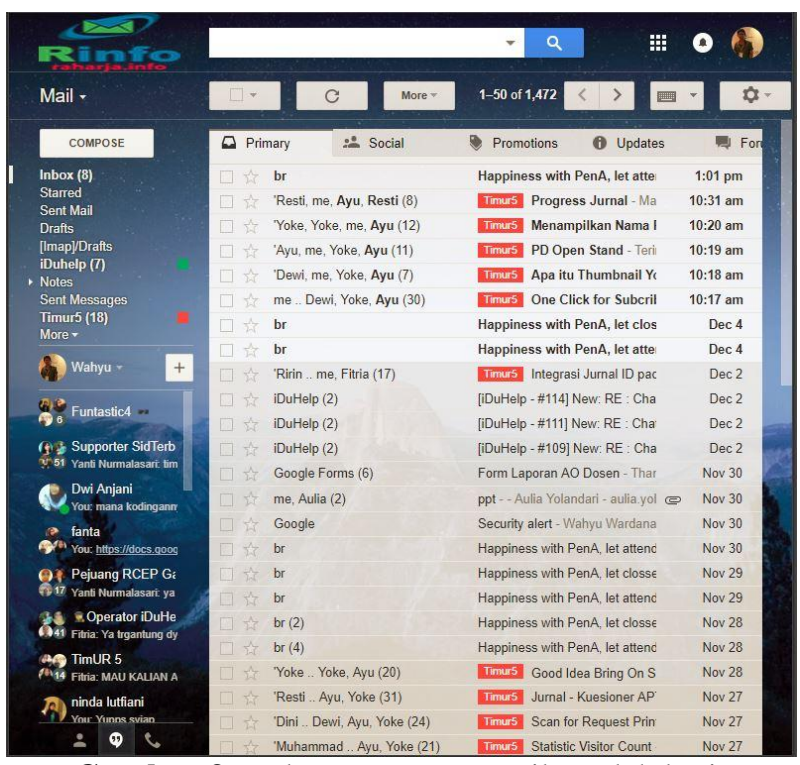

Gambar 3. Halaman utama gmail setelah login

3. Setelah masuk pada tampilan gmail, selanjutnya masuk ke google calendar yang ada pada pojok kanan atas seperti berikut :

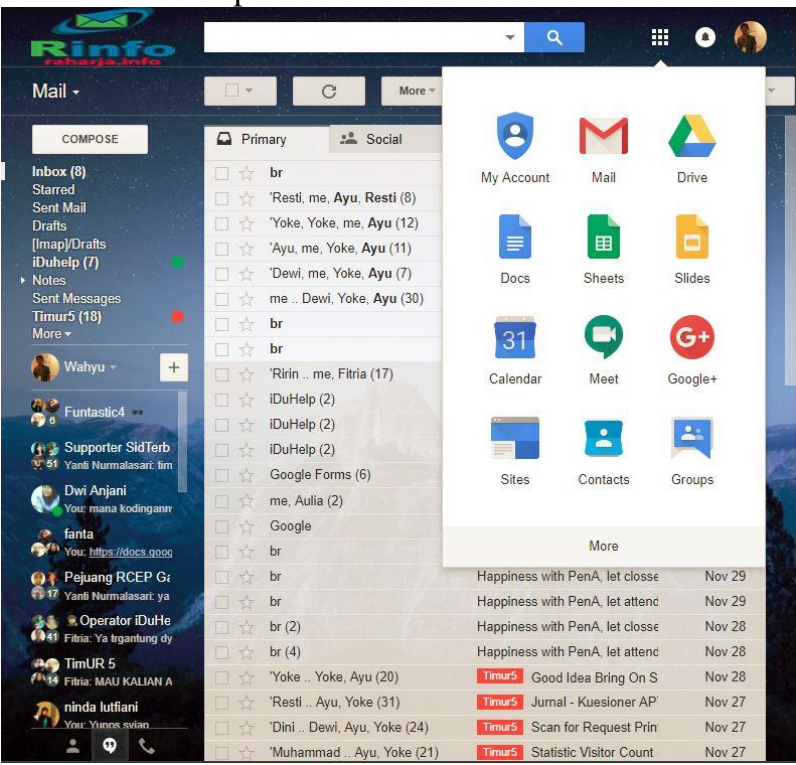

Gambar 4. Masuk bagian google calendar

4. Pada halaman ini barulah dapat membuat agenda atau jadwal. Pada halaman ini juga dapat terlihat semua agenda yang sudah dibuat.

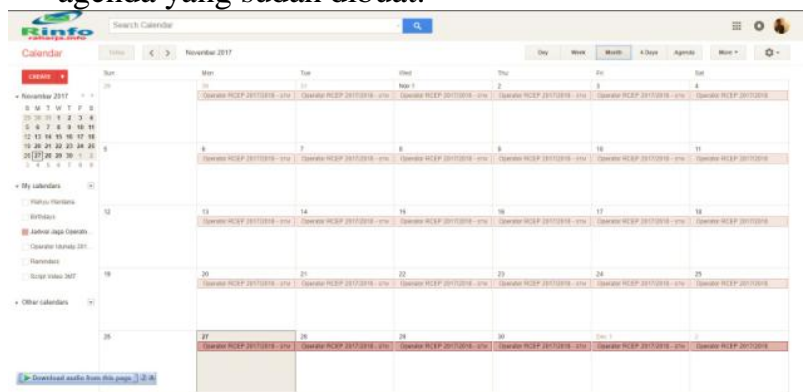

Gambar 5. Tampilan utama setelah masuk google calendar ( by month ). 
5. Membuat agenda pada google calendar

\begin{tabular}{|lll|l|l|l|}
\hline K.g. $7 \mathrm{pm}$ Dinner at Pancho's \\
\hline Calendar
\end{tabular}

Gambar 6. Kotak dialog create event.

Jika user ingin membuat agenda, klik pada bagian kotak tanggal yang diinginkan. Berikan nama agenda yang terdapat pada atas kotak dialog. Tampilannya bisa dilihat pada gambar diatas.

6. Tampilan dialog pada create reminder.

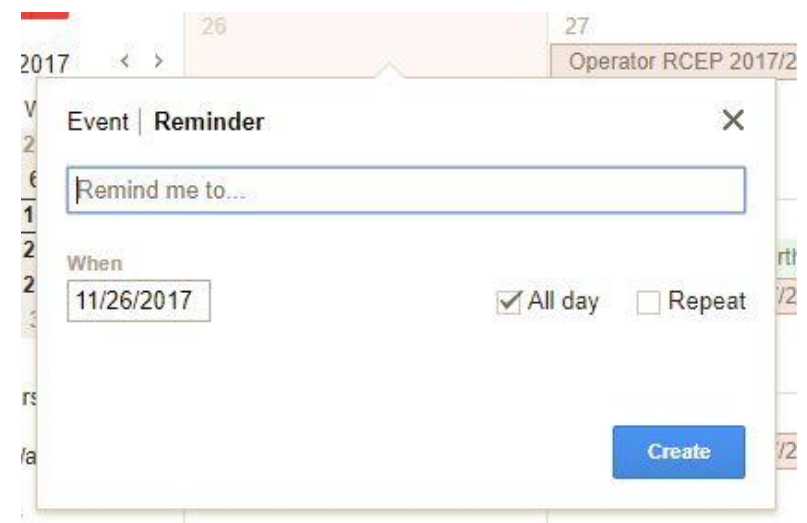

Gambar 7. Kotak dialog create reminder

Ketika user ingin membuat reminder untuk mengerjakan atau melakukan sesuatu hanya lakukan setup pada date yang diinginkan untuk pekerjaan tersebut. Bisa dilakukan repeat reminder atau pengulangan pengingat jika tugas atau pekerjaan tersebut dilakukan setiap minggu atau setiap bulannya. pada hari yang sama.
7. Tampilan dialog pada edit event

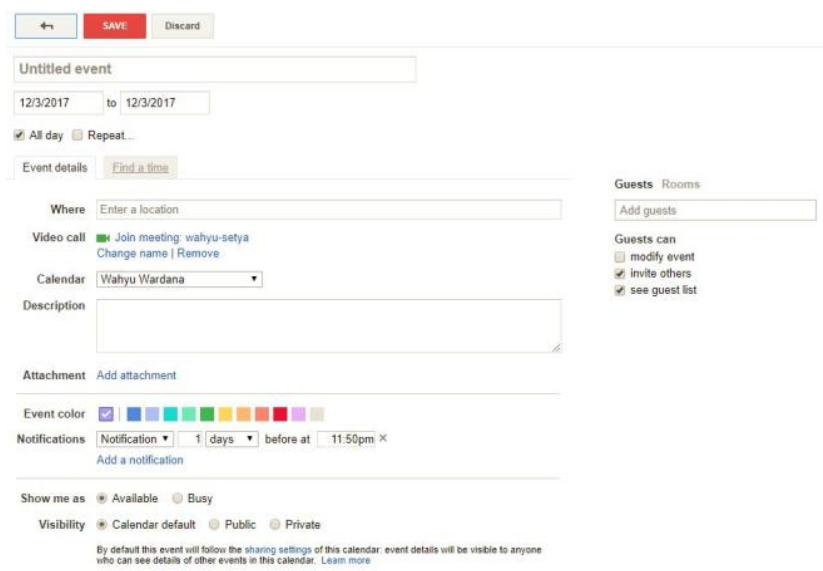

Gambar 8. Kotak Dialog Tampilan Edit Event

Pada kotak dialog ini ditampikan judul event yang akan dibuat, dapat disesuaikan waktunya (dimulai dan berakhir) dari event tersebut. Jika event tersebut dilaksanakan rutin setiap minggu atau bulannya dapat diatur pada kolom repeat. Bisa disesuaikan apakah berulang setiap minggu atau bulan.

Pada kolom description dapat dicantumkan informasi yang ada pada event yang akan berlangsung. User juga dapat menambahkan atau mengurangi peserta. Serta mengatur Visibilitynya default, Public atau Private. Dapat pula diberikan warna pada event dikalendar tersebut.

8. Tampilan Notifikasi Google Calendar

Respon pengguna lain atau peserta lain yang sudah dimasukkan ke dalam sebuat jadwal kegiatan ada tiga macam respon yaitu Accepted, Tentatively Accepted dan Declined.

9. Tampilan Undangan Event Yang Sudah Dibuat User. Berikut merupakan contoh tampilan dari event yang sudah dibuat oleh user.

Invitation: Pra KKP Timur 5 @ Tue May 2, 2017 10am - 10:50am (Wahyu Wardana) Inbox x

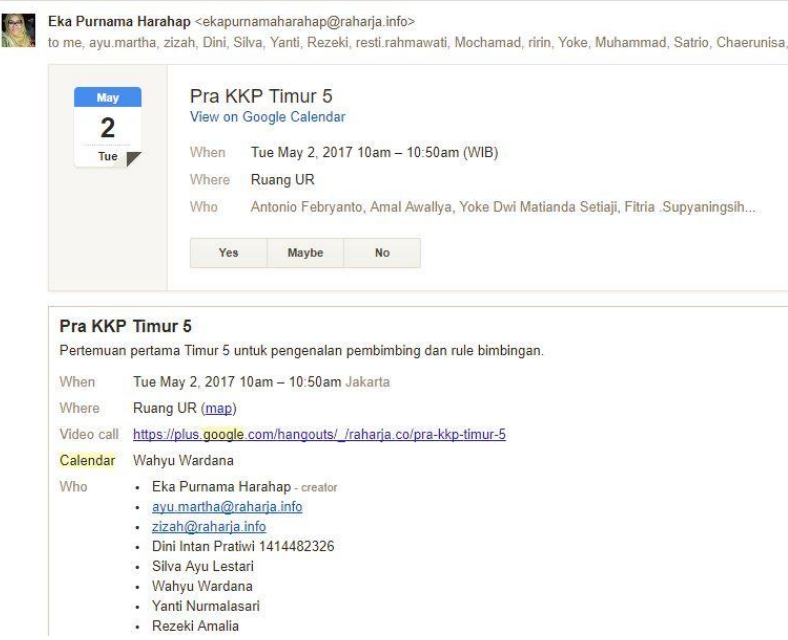

Gambar 9. Tampilan notifikasi mail dari agenda yang sudah dibuat user. 
Invitation: Bayar Uang Kas Fanta @ Weekly on Thursday (Wahyu Wardana)

Resti Rahmawati <resti.rahmawati@raharja.info>

to me, ninda, Mochamad -

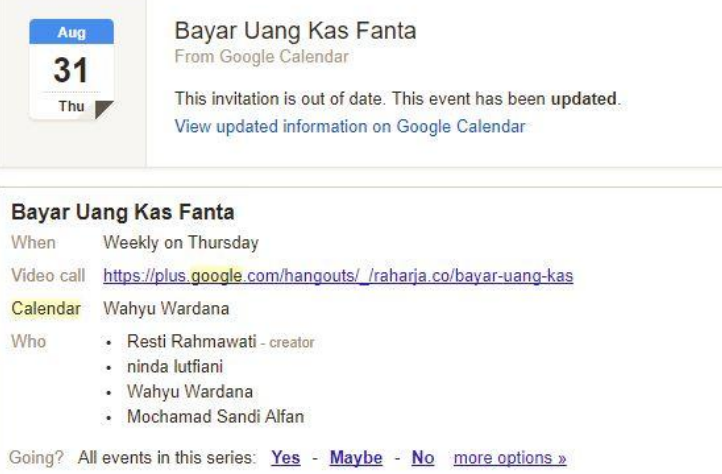

Gambar 10. Tampilan notifikasi mail dari agenda yang sudah dibuat user.

Dari dua gambar diatas dapat dilihat tampilan pengingat agenda yang sudah dibuat. Kapan pengingatnya akan muncul, siapa saja yang masuk dalam agenda, dan ada pilihan yes, maybe dan no di setiap notifikasinya.

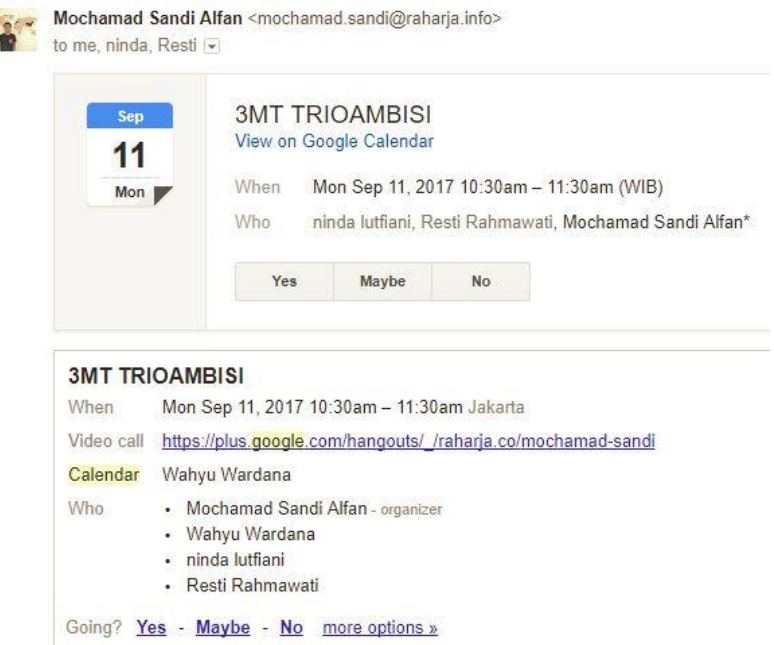

Gambar 11. Tampilan notifikasi email dari agenda yang sudah dibuat user.

GCalendar adalah aplikasi pengingat yang ada dan sudah terintegrasi langsung dengan Gmail sehingga hal ini akan mempermudah dalam hal remider kegiatan bersama. GCalendar sendiri merupakan bentuk kalender digital yang ada didalam google mail itu sendiri. Di dalam GCalendar kita dapat membuat event kegiatan atau untuk mengingatkan kita jika ada tugas yang akan segera jatuh tempo. GCalendar juga dapat digunakan alat reminder bersama. Jika pada kalender digital lain hanya dapat mengingatkan si pemilik gadget, lain halnya dengan GCalendar. GCalendar juga dapat mengingatkan user lain dengan cara menambahkan email pada kolom guests. GCalendar juga memungkinkan untuk mengirimkan reminder pada sebuah grup milis.

Untuk menggunakan Gcalendar pada dasarnya sangat mudah. Pertama, pengguna tentu saja harus mempunyai akun Gmail karena GCalendar merupakan bagian dari Gmail itu sendiri. Setelah pengguna telah login, dapat memilih GCalendar pada bagian GoogleApps yang ada di sebelah kanan atas email. Dalam pembuatan event GCal sangat mudah untuk digunakan. Untuk membuat sebuah jadwal atau event, pengguna hanya perlu melakukan satu klik pada kolom tanggal yang akan dibuat. Selanjutnya, pengguna akan mengisi tempat dimana event tersebut dilaksanakan, kapan waktunya dan siapa saja pesertanya.

Selain itu untuk membuat event, GCalendar juga dapat menjadi pengingat untuk sebuah task atau tugas yang akan jatuh tempo pengumpulannya. Untuk caranya sama, yaitu pengguna hanya melakukan klik pada kolom tanggal tenggat waktu tugas, kemudian klik Reminder. Pada kolom task diisi tentang judul tugas yang akan segera due, atau juga dapat diberikan deskripsi yang lebih rinci mengenai tugas tersebut dan jika sudah selesai dapat klik create.

Dalam GCalendar, pengguna yang telah membuat event pada GCalendar selanjutnya disebut sebagai organizer. User dapat melihat menu edit event, namun hanya organizer yang mempunyai akses untuk mengubah event tersebut bilamana ada perubahan waktu dan tempat maupun dari peserta event yang sudah dibuat. Dalam tampilan ini, user mempunyai banyak hak, seperti terdapatnya menu yang lebih detail lagi mengenai jadwal waktunya dimulai kapan dan berakhirnya kapan, ingin diatur untuk diingatkan dalam waktu yang seperti apa. Sebagai contoh untuk jadwal rapat dapat dibuat per minggu untuk rentang waktu selama berapa lama.

Dalam edit event dalam GCalendar pun memungkinkan si pengguna untuk mengatur notifikasi yang akan muncul, mengatur warna tampilan untuk event kalendernya. GCalendar juga menyediakan fungsi video call dan juga GoogleHangout yang memungkinkan peserta rapat dapat saling berinteraksi dengan rapat tersebut walaupun tidak dapat hadir di tempat rapat tersebut. Selain itu, pengguna juga dapat mengatur peserta rapat (menambahkan atau mengurangi peserta event). Pengguna yang menjadi organizer dapat melihat respon dari peserta event yang sebelumnya sudah diundang dalam GCalendar tersebut. Apakah peserta merespon dengan ya, tidak atau mungkin akan hadirdan juga berapa banyak peserta yang sudah memberi respon.

Pada menu ini, user pun dapat memindahkan kepemilikan event yang sudah pernah dibuat kepada orang lain. User hanya cukup klik bagian menu edit ini, pilih more action lalu pilih change owner. Selanjutnya user tinggal menambahkan alamat Gmail orang yang akan dijadikan pemilik event tersebut. User juga dapat menduplikasi kalender untuk digunakan pada tanggal yang berbeda.

User dapat membuat lebih dari satu notifikasi. Notifikasi yang bisa digunakan dapat berupa pop-up dan atau email. Untuk notifikasi, dapat digunakan juga sebanyak berapapun yang user inginkan. Misalnya, ingin menggunakan email sebanyak $3 x$ dalam rentang waktu yang berbeda atau mengkombinasikan antara pop-up reminder dengan email. 
Penggunaan GoogleCalendar yang tidak terbatas hanya pada satu orang saja membuatnya lebih efisien. Seluruh peserta yang sudah dicantumkan pada event kalendar tersebut dapat menerima notifikasi reminder tersebut. Google Calendar juga mampu mengingatkan secara kelompok atau grup. Untuk penambahan grup pada GoogleCal caranya mirip dengan menambahkan individu, yaitu cukup dengan memasukan milist grup ke dalam daftar peserta event dan disimpan sehingga GoogleCal akan mengingatkan grup tersebut.

Namun, untuk dapat menikmati fasilitas reminder pada GoogleCal ini, user yang mendapat undangan dari GoogleCal harus terlebih dahulu memberikan respon ya dan kemudian dengan otomatis GoogleCal akan mengingatkan user tersebut. Bila user memberikan respon mungkin, untuk beberapa hari berikutnya GoogleCal akan mengirim email undangan yang sama. Bila user memberikan respon tidak, maka GoogleCal tidak akan mengirimi reminder kepada user tersebut.

GoogleCal tentu saja telah memberikan manfaat yang bagus. Pertama tentu saja para user yang dikirimi notifikasi oleh RinfoCal akan menjadi lebih ingat tentang adanya jadwal yang sebelumnya terlupakan dikarenakan notifikasi GoogleCal tidak hanya sekali saja tapi bisa dilakukan berkali-kali secara otomatis. GoogleCal juga membantu organizer dalam hal penghematan waktu dan usaha. Organizer tidak perlu repot-repot untuk menelepon peserta event satu per satu untuk mengingatkan akan sebuah kegiatan yang akan datang. Organizer pun tidak perlu bersusah payah menitipkan pesan bila orang yang dituju tidak ada di tempat karena GoogleCal yang sudah terintegrasi dengan Rinfo ini sifatnya portable atau dapat dibawa kemanapun, dan dengan notifikasi berulang sudah pasti info kegiatan tersebut akan sampai ke orang yang dituju.

\section{Kesimpulan}

Dengan demikian berdasarkan hasil penelitian mengenai Penjadwalan Online menggunakan Google Calendar merupakan salah satu aplikasi berupa kalender digital yang dapat dimanfaatkan untuk membuat jadwal dan pengingat pengguna. Berkaitan dengan kegiatan Tridharma yang ada di Perguruan Tinggi hal ini membantu sekali bagi para mahasiswa yang sedang menjalankannya. Berfungsi sebagai pengingat kepada masing-masing mahasiswa agar tidak lupa dalam tugasnya. Dalam penggunaan Google Calendar sebagai sarana penunjang Tri Dharma Kampus Raharja. Dalam implementasi pada setiap periodenya untuk senantiasa di-update pada bagian guest. Karena setiap periode berganti mahasiswa. Bisa untuk menyesuaikan dengan perubahan-perubahan mulai dari segi interface dan fitur yang di tambahkan oleh google sendiri setiap ada update.

\section{Daftar Pustaka}

[1] Rahardja, U., Tiara, K., \& Wijaya, R. I. T. (2014). Penerapan Rinfo Sebagai Media Pendukung Untuk Proses Pembelajaran Pada Perguruan Tinggi Raharja. Jurnal CCIT, 8(1).
[2] Handayani, I., Aini, Q., \& Oktavyanti, Y. (2015). Penggunaan RinfoCal Sebagai Aplikasi Pengingat (Reminder) Kegiatan Akademik Pada Perguruan Tinggi. CCIT Journal, 9(1), 13-26.

[3] Mukhtar, M., Mustika, I. W., \& Setiawan, N. A. (2017, January). Perancangan Sistem Penjadwalan untuk Manajemen Penggunaan Ruangan Berbasis Google Calendar. In Prosiding Seminar Nasional ReTII.

[4] Ferdiansyah, Y., Susilo, B., \& Andreswari, D. (2014). PEMANFAATAN GOOGLE CALENDAR SEBAGAI SMS ALERT DALAM SISTEM MONITORING JARINGAN KOMPUTER (Studi

Kasus: Jaringan Komputer Universitas Bengkulu) (Doctoral dissertation, Universitas Bengkulu).

[5] Ramadhan, T., \& Utomo, V. G. (2014). Rancang Bangun Aplikasi Mobile untuk notifikasi Jadwal Kuliah Berbasis Android (Studi Kasus STMIK Provisi Semarang). Jurnal Teknologi Informasi dan Komunikasi, ISSN, 2087-0868.

[6] Barovih, G. (2016). Desain Sistem Informasi Penjadwalan Laboratorium Terbuka (Studi Kasus: Laboratorium Terbuka STMIK Palcomtech). SISFOTENIKA, 6(1).

[7] Handayani, I., Kusumahati, H., \& Badriah, A. N. (2017). Pemanfaatan Google Spreadsheet Sebagai Media Pembuatan Dashboard pada Official Site iFacility di Perguruan Tinggi. SISFOTENIKA, 7(2), 177-186.

[8] Suryati, P., \& Kurniawati, D. (2016). APLIKASI PENJADWALAN KOAS DENGAN METODE BRANCH AND BOUND. JIKO (Jurnal Informatika dan Komputer), 1(2).

[9] Destiningrum, M., \& Adrian, Q. J. (2017). Sistem Informasi Penjadwalan Dokter Berbassis Web Dengan Menggunakan Framework Codeigniter (Studi Kasus: Rumah Sakit Yukum Medical Centre). Jurnal Teknoinfo, 11(2). 